\title{
Autosomal dominant palmoplantar hyperkeratosis and sensorineural deafness in three generations
}

\author{
M Sharland, N R Bleach, P D Goberdhan, M A Patton
}

\begin{abstract}
A family is presented with autosomal dominant progressive palmoplantar hyperkeratosis, which is invariably associated with a slowly progressive, bilateral, high frequency, sensorineural hearing loss. The family show no other ectodermal abnormality. The differential diagnosis and possible mechanisms are discussed. This family appears to represent a unique variant in the hyperkeratosis-deafness association.
\end{abstract}

The association between hearing loss and various dermatological conditions has been well described. ${ }^{1}$ The combination of sensorineural hearing loss (SNHL) and palmoplantar hyperkeratosis has also been recognised. ${ }^{2-6}$ However, previous reports include evidence of widespread ectodermal dysplasia (pili torti, dental anomalies, alopecia, nail dystrophy), or a variable relationship between the inheritance of skin changes and hearing loss. We present a family with characteristic, progressive palmoplantar hyperkeratosis invariably associated with a progressive, high frequency, sensorineural hearing loss, but without evidence of other ectodermal abnormality.

\section{Family history}

The 4 year old proband presented at 18 months of age with a suspected hearing loss. The initial impression was one of serous otitis media. Subsequent audiometric assessment confirmed a bilateral, high frequency SNHL, although there was no skin abnormality. After recognition of the familial basis of the hearing loss, further family members were examined, photographed, and audiometrically assessed. The pedigree is shown in fig 1 . Typical familial palmoplantar hyperkeratosis is shown in figs 2 and 3. The clinical history was similar in all affected family members. A mild hearing loss became noticeable in early childhood, with skin changes developing at a later date, usually between the ages of 5 and 7 years. The skin showed thickening and dryness over the palms and soles, with sharply demarcated margins. Accidental trauma to the affected areas exacerbated the hyperkeratosis, which also showed marked progression during pregnancy. Both the hearing loss and the palmoplantar hyperkeratosis were slowly progressive with age.

The proband's 6 year old sister had a typical sensorineural hearing loss, with only very mild keratotic changes on her feet. It is important to note that no affected family member had any digital or dental anomalies, significant alopecia, or nail dystrophy. There were no visual abnormalities, no abnormal sweating, nor any mental retardation. One family member underwent karyotyping and had urine analysis for amino acids performed, both of which were normal.

\section{Audiological assessment METHOD}

Before testing, all family members were examined by an ENT surgeon to exclude any external or middle ear abnormalities. All audiometric testing was performed on the
Department of Genetics, St George's Hospital Medical School, Cranmer Terrace, London SW17 0RE. M Sharland M A Patton

Departments of ENT and Audiology, Mayday Hospital, Croydon.

N R Bleach

P D Goberdhan

Correspondence to Dr Sharland.

Received 4 January 1991. Revised version accepted 5 April 1991.

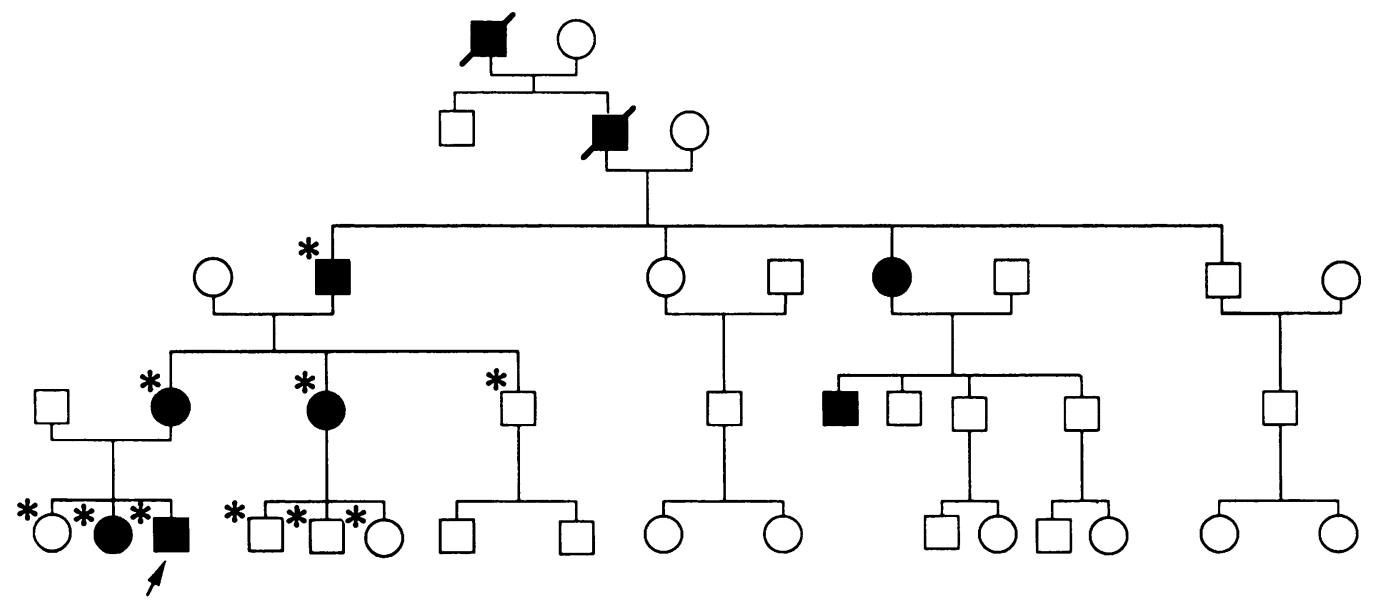

* Examined and audiometric testing performed

Figure 1 Pedigree of family. 
Figure 2 Typical palmoplantar.

hyperkeratosis in an adult hand
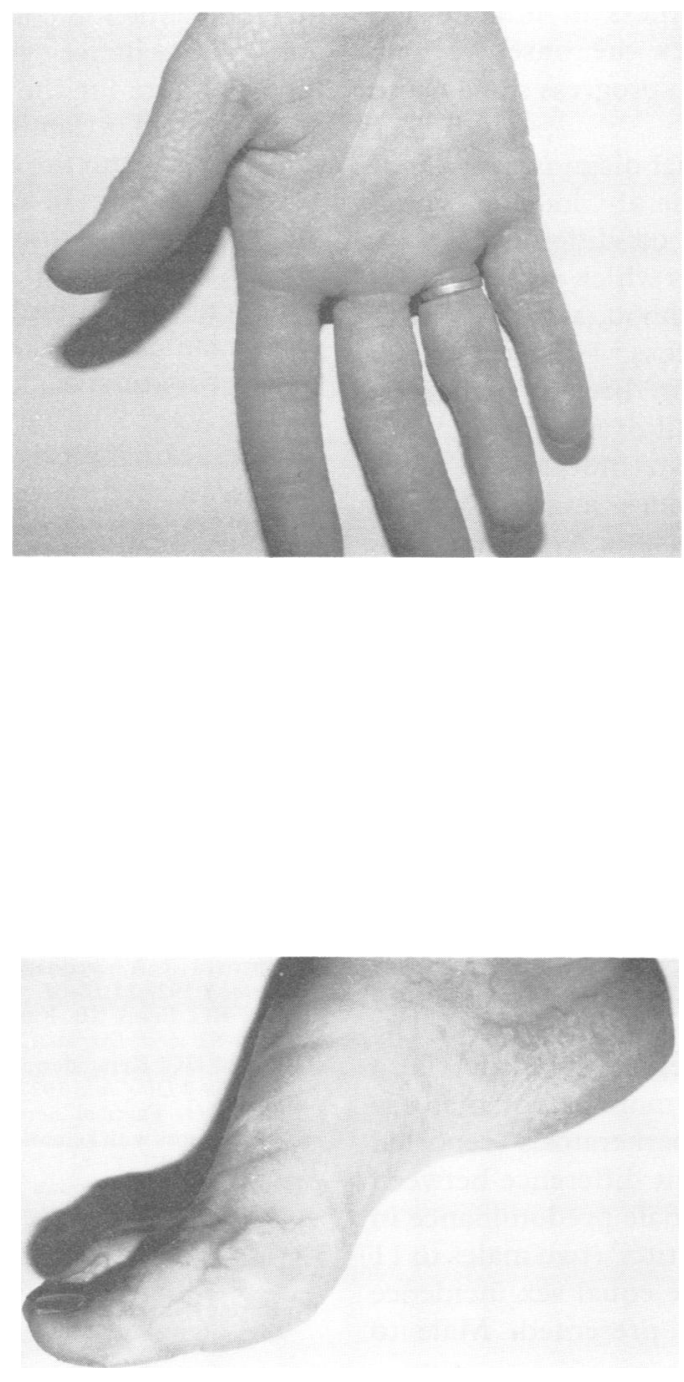

Figure 3 Typical

palmoplantar

hyperkeratosis in an adult foot. same day by a single, experienced audiometrician under standard conditions in a soundproof room. A Grayson Stadler GSI 16 audiometer was used, presenting test tones via headphones. Tympanometric testing was performed with a Grayson Stadler GSI 33 middle ear analyser.

\section{RESULTS}

The 4 year old proband had normal tympanic membranes and unaffected palmar and plantar skin. Audiometry confirmed a bilateral high frequency SNHL (fig 4A). The proband's mother, aged 31 years, showed markedly affected hands and feet with obvious hyperkeratosis. Her tympanic membranes were normal but audiometry confirmed a similar high frequency SNHL (fig 4B). Tympanometry was normal, indicating good middle ear function. Features were suggestive of a cochlear type of hearing loss. All affected family members (see pedigree) showed a similar high frequency loss, which was most severe in the oldest (67 years). In contrast, the proband's maternal uncle, aged 33 years, showed no evidence of skin changes and had normal hearing, as did an unaffected 8 year old sib.

\section{Discussion}

There are many disorders, both dominant and recessive, characterised by palmar and plantar hyperkeratosis, ${ }^{7}$ and the association between hyperkeratosis and sensorineural deafness has been previously noted. ${ }^{2-6}$ The family we describe appears to have palmoplantar hyperkeratosis and high frequency sensorineural hearing loss inherited as an autosomal dominant
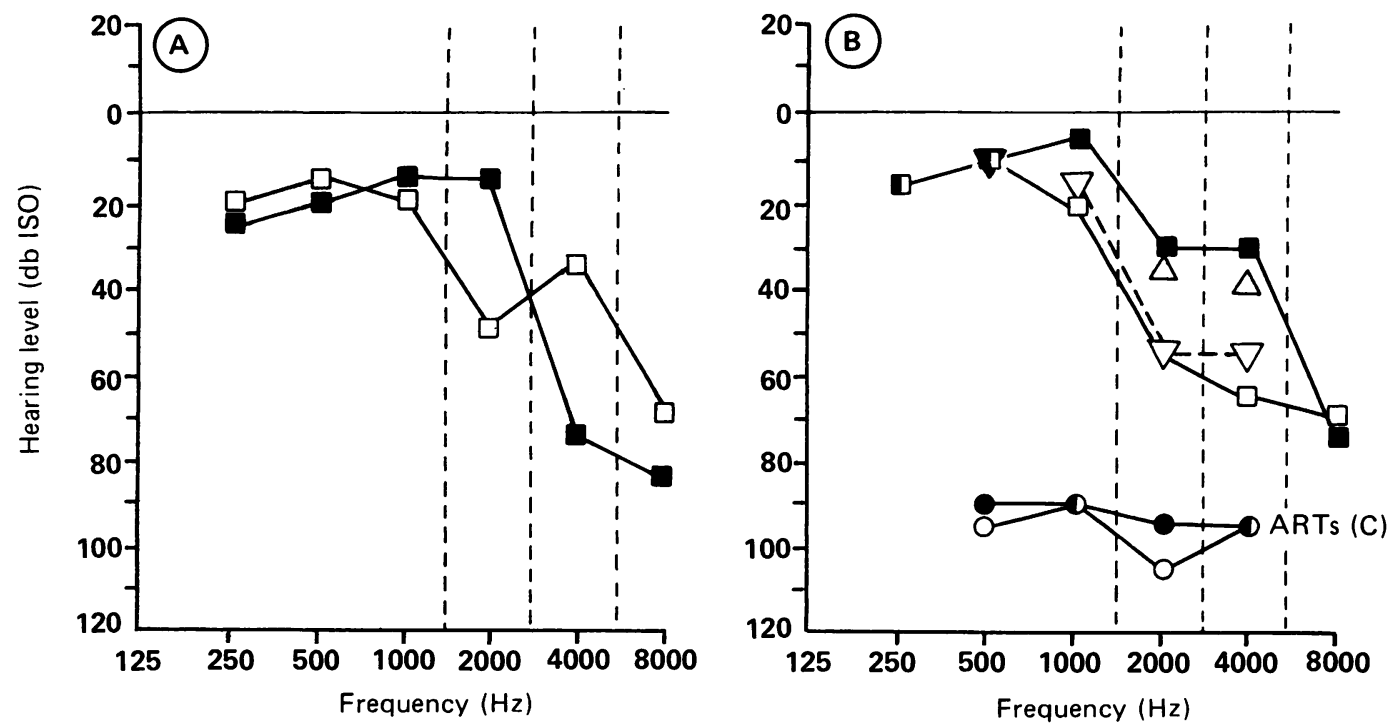
trait. The onset of deafness in infancy and early childhood predates the onset of skin changes, after which both progress slowly with age.

Of the many differential diagnoses, the hidrotic ectodermal dysplasia of Clouston type is an autosomal dominant condition, with palmoplantar hyperkeratosis which is slowly progressive from early childhood, associated with a sensorineural hearing loss. ${ }^{2}$ However, it has been described mainly in French pedigrees, and there is universal nail dystrophy and alopecia. Keratoma hereditare mutilaris de Vohwinkol ${ }^{3}$ similarly combines a sensorineural hearing loss with palmoplantar hyperkeratosis, but the hyperkeratosis is more severe with widespread extension which causes marked digital constriction. Olmsted syndrome includes a variety of abnormalities associated with palmoplantar hyperkeratosis, but all reports to date have been sporadic and the hyperkeratosis tends to affect the perianal region. ${ }^{4}$ Bititci ${ }^{5}$ reported a similar three generation pedigree with combined sensorineural deafness and palmoplantar hyperkeratosis. The deafness had a similar age of onset to the family in this report, but progressed more quickly leading to speech impairment. The hyperkeratosis in the report of Bititci $^{5}$ also appears to be milder and more patchy than the progressive diffuse hyperkeratosis reported here. The most significant difference between the two reports is the female predominance in the family reported by Bititcis (two males to 11 females) compared to the equal sex incidence occurring in the family presented. Male to male transmission confirming autosomal dominant inheritance for this association is reported here for the first time. Hatamochi et $a l^{6}$ described a family with almost identical skin changes, but the hyperkeratosis developed as late as 16 years of age and could be inherited independently of the associated deafness. In conclusion, we propose that this family presents a new syndrome of autosomal dominant palmoplantar hyperkeratosis combined with a slowly progressive, high frequency, cochlear hearing loss. The deafness precedes the skin changes, but the two abnormalities never appear as isolated defects. This appears to be a purely ectodermal syndrome, and we suggest that the combination of abnormalities could be explained by a primary disorder of keratin.

We wish to thank Christine Turton (Audiometrician) and Inga Ferm (Audiological Scientist) for performing the audiograms and ensuring appropriate and accurate testing of the family.

1 Koningsmark BW. Hereditary deafness in man. $N$ Engl $f$ Med 1969;13:713.

2 Clouston HR. A hereditary ectodermal dystrophy. Can Med Assoc F 1929;21:18-31.

3 Gibbs RC, Frank SB. Keratoma hereditare mutilaris (Vohwinkel). Arch Dermatol 1966;94:619-25.

4 Olmsted HC. Keratoderma palmaris et plantaris congenitalis. Am $\mathcal{F}$ Dis Child 1927;33:757-64.

5 Bititci OO. Familial hereditary progressive sensorineural hearing loss with keratosis palmaris and plantaris. $f$ Laryngol 1975;89:1143-6.

6 Hatamochi A, Nakagawa S, Ueki H, Miyoshi K, Inchi I, Konigsmark BW. Hereditary deafness in man. $N$ Engl $\mathcal{f}$ Med 1969; 281:713-20.

7 Ebling FJ, Marks R, Rook A. Disorders of keratinisation. In: Rook A, Wilkinson DS, Ebling FJG, Champion RH, Burton JL, eds. Textbook of dermatology. 4th ed, vol 2. Oxford: Blackwell Scientific Publications, 1986. 